\title{
Deposition of Pesticide to the Soil and Plant Retention During Crop Spraying: The Art State
}

\author{
Asma Allagui ${ }^{1,2}$, Hassouna Bahrouni ${ }^{1} \&$ Youssef M'Sadak ${ }^{2}$ \\ ${ }^{1}$ National Institute of Research in Rural Engineering, Water and Forestry, University of Carthage, Tunisia \\ ${ }^{2}$ Higher Institute of Agronomic Sciences in Chott Mariem, University of Sousse, Tunisia \\ Correspondence: Hassouna Bahrouni, National Institute of Research in Rural Engineering, Water and Forestry, \\ University of Carthage, P.O. Box 10, Street Hedi Karray, PC 2080 Ariana, Tunisia. Tel: 216-9863-2247. E-mail: \\ bahrouni.hassouna@iresa.agrinet.tn; h.bahrouni@gmail.com
}

Received: August 7, 2018

Accepted: September 15, 2018

Online Published: November 15, 2018

doi:10.5539/jas.v10n12p104

URL: https://doi.org/10.5539/jas.v10n12p104

\begin{abstract}
Environment pollution related to pesticides has been confirmed by the scientific community for a long time, but the available information on the impact of this phenomenon on human health and the ecosystem are still insufficient. Contamination of the environment can occur through various pathways, ground deposits during the application of pesticides to crops are one of those pathways. The retention rate of sprayed droplets is an important factor both for the efficacy of the phytosanitary treatment and the quantities of lost pesticides on the ground. This paper presents an overview of factors that affect spray droplet behavior, involved process in sprayed drop fate and the mainly techniques for measuring pesticide deposits to the ground and plant retention. We present studies that have focused on pesticide retention and soil deposition during crop spraying in relation to sprayer equipment, used formulation and climatic factors. Plant retention and pesticide deposits during spray is a complex problem depending mainly on physical sprayer parameters, climatic conditions, spray properties and chemical formulation. By illustrating the large variety of analytical methods during the recently years, it aims to explain that it is always possible to assess the impact of pesticides in all compartments of the environment. The use of concerned molecules and natural collectors is the safest to evaluate the real situation, but the use of tracers and artificial targets is both very reported and safety for the environment.
\end{abstract}

Keywords: pesticide application, plant retention, soil deposits, measuring, environmental factors

\section{Introduction}

Pesticides are used in plant protection to improve agricultural production and to produce a good yield. The poor efficiency of the spraying process leads to economic losses, environmental contamination, reducing in biological efficacy of the applied pesticide. Public authorities' preoccupation with those problems has increased significantly during the last few years, particularly in relation to both health and environmental risks. One of the main causes of this problem could be the pollution of the environment by transferring polluting agents from crop-growing areas to natural resources, via different pathways. The maximization of the spray retention on plants and the reducing of the off-target losses is one of the key remedies for both preserving the environment and improving the effectiveness of plant protection. During spraying, the small droplets are not retained by the plant and are drifted by the air. Large droplets, also, cannot adhere to the leaf, because they runoff from the surface after bouncing or shattering and are retained by lower leaves surface or will deposit on the soil (Cox \& al., 2000).

Bahrouni (2010) showed that in winter wheat, in the Tunisian context, soil deposition of pesticide under plants, vary from 46 to $92 \%$ of the sprayer rate (for details, see Table 1), while the retention is only 5 to $29 \%$. Graham-Bryce (1977) found that retention rate, in \% of the dose/ha, was only $0.03 \%$ for the "Dimethoat" on the bean and 2.9\% when applying "Disulfaton" on wheat. According to Gyldenkaerne et al. (1999), depending on the growth stage of BBCH (Note 1), soil deposition of pesticide in spring barley can reach $84.8 \%$ of volume / ha. On cereals, BBCH Stage 10-19, Becker et al. (1999) estimated the retention at $25 \%$ of the applied dose. Under the same conditions, the soil deposition was evaluated by FOCUS (2002) at $75 \%$. In Olufsdotter and Streibig (1997), soil deposition during weed control and fungal treatment of winter wheat, with a vegetative cover of $20-40 \%$, was 62 to $81 \%$ of the dose. 
All these results confirm that the losses of pesticides on the ground are always high while the retention on the plants remains low.

Table 1. Pesticides deposits and plant retention ( $\%$ of applied) under laboratory conditions for a forward speed of $7 \mathrm{~km} /$ hour, a temperature of $15^{\circ}$ and a relative humidity of $65 \%$ (Bahrouni, 2010)

\begin{tabular}{|c|c|c|c|c|c|c|}
\hline Nozzle & $\begin{array}{l}\text { Pressure } \\
\text { (bar) }\end{array}$ & $\begin{array}{l}\text { Volume Median } \\
\text { Diameter VMD } \\
(\mu \mathrm{m})\end{array}$ & $\begin{array}{l}\text { Nozzles height } \\
(\mathrm{m})\end{array}$ & $\begin{array}{l}\text { Soil deposits } \\
(\%)\end{array}$ & $\begin{array}{l}\text { Plant retention } \\
(\%)\end{array}$ & $\begin{array}{l}\text { Volatilisation } \\
(\%)\end{array}$ \\
\hline \multirow{4}{*}{ Albuz, Flat-fan 11002} & \multirow{2}{*}{4} & \multirow{2}{*}{127} & 0.5 & 59 & 29 & 12 \\
\hline & & & 0.8 & 46 & 28 & 26 \\
\hline & \multirow{2}{*}{2} & \multirow{2}{*}{144} & 0.5 & 67 & 22 & 11 \\
\hline & & & 0.8 & 65 & 20 & 15 \\
\hline \multirow{4}{*}{ Albuz, Flat-fan 11003} & \multirow{2}{*}{4} & \multirow{2}{*}{162} & 0.5 & 71 & 21 & 8 \\
\hline & & & 0.8 & 66 & 20 & 14 \\
\hline & \multirow{2}{*}{2} & \multirow{2}{*}{210} & 0.5 & 76 & 18 & 7 \\
\hline & & & 0.8 & 76 & 15 & 9 \\
\hline \multirow{4}{*}{ Albuz, Flat-fan 11006} & \multirow{2}{*}{4} & \multirow{2}{*}{234} & 0.5 & 86 & 9 & 5 \\
\hline & & & 0.8 & 84 & 8 & 8 \\
\hline & \multirow{2}{*}{2} & \multirow{2}{*}{322} & 0.5 & 92 & 5 & 2 \\
\hline & & & 0.8 & 90 & 5 & 5 \\
\hline
\end{tabular}

This article is a review of measurement techniques and simulation studies that had been conducted over years to characterize spray droplet pattern to reach the target and to maximize the efficiency of spray crop protection. We will present studies that have focused on pesticide retention and soil deposition during crop spraying in relation to sprayer equipment, used formulation and climatic factors. First, the state of the art related to factors that are involved in spray droplets fate, such as spray equipment, physical and chemical formulation properties, climatic factors and leaves surface characteristics, is presented. Next, the process involved in spray droplet deposit and retention is discussed. Finally, the methods to evaluate plant retention and pesticides losses to soil, both by simulation using tracer and by direct pesticides measurement, including sampling technics and collectors, are described.

\section{Involved Factors in Spray Droplet Deposition in the Soil and Their Retention on Plants}

The high spray retention on the target leaves is a solution to achieve better result in more uptake by the plants and less pesticide wasted into the environment. On the other hand, the biological efficacy of the pesticide is depending of the active ingredients which is influenced by the behavior of the droplet on the leaves surface. This means that the droplet size spectrum of a spray application is an important factor affecting the efficiency and the deposition of the spray application. It strongly determines the drop behavior on plant and their fate. That's why, the British Crop Protection Council (BCPC) and American Society of Agricultural Engineers (ASAE) have classified agricultural sprays based on droplet size. Thus, several studies have been carried out by the scientific community around the world to study parameters affecting retention on plants and deposits on the ground which are strongly resulting from the droplet properties. Droplets pesticide emission during application is controlled by many factors such as physical equipment parameters, climatic conditions, physiochemical properties of the formulation and target surface properties. But they can be divided into two mainly categories: technical and environmental factors. According to Teske et al. (2002), the parameters affecting the deposition of the droplets are spray pressure, liquid flow rate, air velocity and shear across the atomizer, spray physical properties (viscosity, specific gravity and surface tension) and atmospheric conditions. Wilson et al. (2003) added drop velocity and diameter resulting from equipment parameters (forward speed, nozzle, rate, pressure, etc.), spray formulation properties (dynamic surface tension, dynamic viscosity, etc.) and target surface characteristics (leaf angle, hydrophobicity, growth stage, etc.). Recently, Massinon and Lebeau, (2013) found that the parameters affecting spray deposition are nozzle type and size, the volume applied per hectare, the formulation, the used surfactant, the plant architecture, the leaf surface, the leaf orientation, the contact angle, the wettability and the surface tension. Hewitt et al. (2001) studied the effect of liquid properties and nozzle design on drift potential, and they confirmed that adjuvant has a direct effect on the break-up of spray through nozzle type, droplet size distribution and drift potential. Wolf et al. (2004) demonstrated that the air induction nozzles provide a coarse spray that increased deposition on vertical and horizontal artificial targets like cereal canopy, also the increasing spray angle between double nozzles increased spray deposits on vertical artificial targets. Nuyttens et al. (2007b) 
confirmed that the ideal nozzle pressure combination will maximize spray efficiency for depositing and transferring a lethal dose to the target, while minimizing off-target losses such as spray drift and user exposure.

In an earlier study, Furmidge (1962) recognized the importance of plant properties in runoff phenomenon of droplets on leaf surface of the vegetation. Forster et al. (2005), Mercer et al. (2007) found that droplets behavior on the plant is strongly affected by the roughness and the inclination angle of the leaf. This is determined by two factors: the leaf area index (LAI) and the leaf cuticle wax, which vary from plant growth and plant canopy.

\subsection{Droplet Properties}

The amount of surfactant added in the formulation of pesticide is an important factor improving the efficacy of the coverage on leaves plant depending on the hydrophobicity and wettability of the leaf surface (De Ruiter et al., 1990). Authors tested the efficacy of surfactant with the fluorescent tracer with low-temperature scanning electron microscopy technique to investigate the influence of leaf surface microstructure on retention of droplets.

The dynamic surface tension of pesticide is depending on the surfactant added to the solution or the liquid proprieties on retention. It can improve pesticide application efficiency and effectiveness but the quantifications of the accuracy amount of adjuvant added in the formulation remain studied case. Xu et al. (2011) determined the droplet spread and evaporation of single droplets released from a micro syringe to waxy and hairy leaves with different spray formulations of adjuvant concentration. They proved that the formulation has a considerable impact on the homogeneity of spray coverage on hydrophobic leaf surfaces to reduce pesticide use by farmer and decrease the risk of contamination of the environment. The formulations and the adjuvants must be optimized to maximize spray droplet retention by leaves (Massinon \& Lebeau, 2013).

Forster et al. (2012) reported that the international requirements recommend the use of spray droplets with diameter $>150 \mu \mathrm{m}$ to reduce the risk of a drift during spray applications. The small drifting droplets will be retained if they are intercepted by the target and larger droplets travelling at higher velocities, may bounce or shatter on interception, leading to low retention volume at the surface. Figure 1a illustrates the bounce and shatter predictions for water droplets (surface tension $=72 \mathrm{mN} / \mathrm{m}$ ) ranging in size and impact velocity, impacting a very difficult to wet plant species.

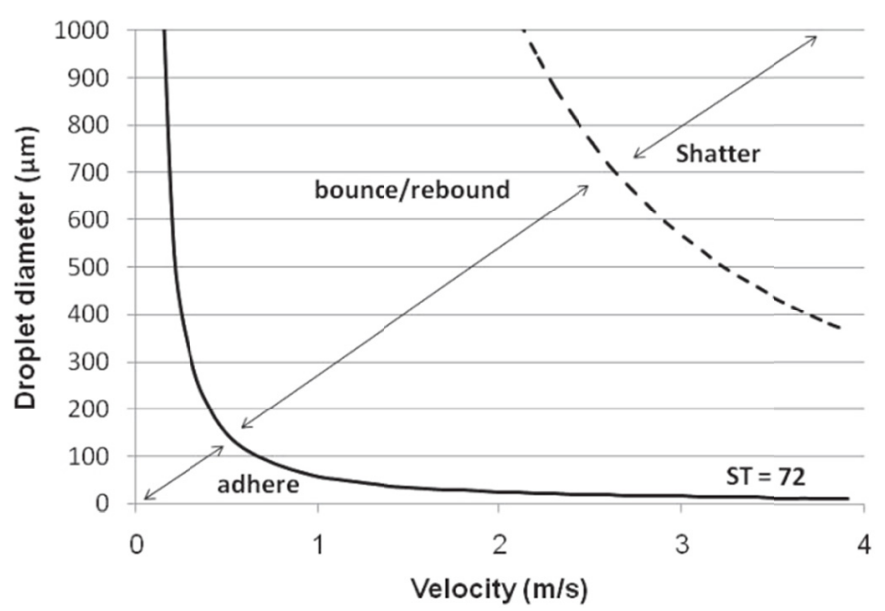

Figure 1. Droplet diameter $(\mu \mathrm{m})$ plotted against droplet velocity $(\mathrm{m} / \mathrm{s})$ to illustrate the predicted bounce (solid line) and shatter (dashed line) lines for spray droplets containing water $(72 \mathrm{mN} / \mathrm{m})$, impacting a very difficult-to-wet species (Forster et al., 2012)

To describe the droplet distribution, Hoffmann and Hewitt (2005) used DV0.5 (the median droplet diameter), DV0.1 and DV0.9 (Note 2). DV0.1 is often used to estimate the portion of droplets that can be transferred by drift. The relative span factor (RSF) measures the width of the droplet spectra around the DV0.5 and is calculated using the following equation:

\subsection{Plant Properties}

$$
\mathrm{SF}=\frac{\mathrm{DV}_{0.9}-\mathrm{DV}_{0.1}}{\mathrm{DV}_{0.5}}
$$

According to Taylor and Shaw (1983), the crop structure and the leaves proprieties (surface, shape and 
orientation) are the main factors affecting the droplets distribution and reducing retention. De Ruiter et al. (1990) explained that the most important factor affecting the deposition is the nature of the cuticular surface (crystalline epicuticular waxes, hairs, edges, veins, roughness, hydrophobicity, etc.). Mechanisms for the wetting of leaf surfaces by agrochemicals are reviewed in Taylor (2011). The wettability of leaves surface depends on the hydrophobicity of the leaves structure influenced by the growth stage, the position of soybean leaves and this potentially influences the performance, selectivity and compatibility of foliar pesticides applied. Moreover, the adjuvants formulations can overcome the low wettability. So, the wetting of leaf surfaces has long been known to govern retention and been the subject of numerous theoretical studies on lotus effect or superhydrophobicity. The contact angle of the droplet decreases from being advancing to receding and the droplet will lose energy and recoil due to surface tension. The droplet lost by drop rebound have to be limited or avoided although their negative effects can be reduced or absent in very dense canopies (species, growth stage and surface wettability), an optimal drop impact energy should be found to limit undesirable effects.

\section{Involved Process in Spray Droplet Deposition in the Soil and Their Retention on Plants}

Many researchers developed mathematical models to describe droplet impact on leaf surfaces to understand spray crop retention process (Becker et al., 1999; Forster et al., 2005; Gyldenkaerne et al., 1999; Olufsdotter \& Streibig, 1997; Cox et al., 2000). New parameters have been added to the spray droplet adhesion model developed by Forster et al. (2005) and improved by Nairn et al. (2013) to a process-driven spray retention model including leaves hairs parameters. Another model was established by Massinon et al. (2017) and the outcomes as computed from logistic regression models related to the Weber number define the destiny of the droplet when reaching a surface. Forster et al. (2012) determine the destiny of a droplet in four patterns: deposition, retention, uptake and translocation.

When the droplet impinges on plants, they experience different behaviors associated with impact, rebound, splash, slide, retention, evaporation, adsorption on the target surfaces (Jia \& Zhu, 2015). The three outcomes of the droplet impacting a leaves surface are potentially adhesion, rebound or shatter, depending on the kinetic energy of the released droplet from the nozzle determined by the mass and the velocity (Boukhalfa et al., 2014). Authors concluded that for an optimal spray retention, the droplets that impact the plant surface must remain on the plant and the volume percentage of adhering droplets will be maximized. The rebound and shatter could also contribute to final retention (Zwertvaegher et al., 2014).

The volumetric proportions of adhesion on first impact alone are not enough to accurately predict retention and the method needs improvement to measure other variables, such as diameter, velocity and reflection angle from rebounding and secondary droplets, needed to improve retention models (Zwertvaegher et al., 2014).

Maximizing pesticide application efficiency requires therefore good control of droplet size and velocity distributions. Mechanisms for the adhesion, retention, to bouncing and splashing of the spray droplet on leaf surfaces and the different droplet regime (Wenzel sticking, Cassie and Baxter wetting regime, etc.) are reviewed by Boukhalfa et al. (2014).

The Weber number is an important factor leading to a modification on the impact of the droplet to the target surface. The Weber number $(\mathrm{We})$ is defined as the dimensionless ratio between droplet kinetic energy in the normal direction to the surface and its surface energy:

$$
\mathrm{We}=\frac{\rho(\mathrm{Vn})^{2} \mathrm{D}}{\delta}
$$

where $\rho$ is the liquid density, $V n$ is the normal droplet velocity to the impacted surface, $D$ is the droplet diameter and $\sigma$ is the formulation equilibrium surface tension (Zwertvaegher et al., 2014).

If the losses energy is low enough, the droplet will bounce or rebound of the leaf, but if the energy is great, the droplet adheres. If the losses are too great then insufficient energy remains for rebound and the droplet adheres (Forster \& al., 2012). If a droplet hits the surface with high energy on the surface tension of the leave can't maintain it, the drop can shatter into finer droplets (Mercer et al., 2007). The droplet reaches its maximum spread when the kinetic energy is converted to potential energy.

\section{Techniques for Measuring Pesticide Deposits to the Ground and Plant Retention}

Several methods can be found in the literature for the measurements of pesticide deposits. They rely either on the use of a tracer or in direct measurement of the used pesticides. This last solution is not usually elected because of the impact of the pesticide and the cost of the analyzes which is usually made through GC/MS. On the contrary, tracer or dyes are commonly used by researchers. 


\subsection{Tracers}

They are early used to simulate spray drop pesticide comportment in filed and in laboratory studies. A good tracer must be easily and highly recovered from both artificial and natural targets. The ideal tracer is a substance that can be visualized in the dry and can be recovered quantitatively from the natural or artificial surface (Palladini et al., 2005). Many types of tracers have been used to simulate the deposition of pesticides on the studied collectors with and without the addition of the non-ionic surfactant. The selection of the tracer to be used must consider the following important criteria: a high sensitivity to detection, quickly quantitative in analyzes, solubility in the spray mixture, low significant effect on sprayed droplet, can be analyzed by the equipment, stable, nontoxic, and with a moderate cost (Yates \& Akesson, 1963). The recovery of the tracer deposit rate is assessed by comparing the amount of measured tracer to the amount of applied tracer and may be affected by dye degradation (sun exposure), background deposits (substances with properties similar to the natural dyes emitted by the leaves) and the process of extraction. Cerqueira et al. (2012) reported that the selection and reliability of quantitative analyzes methods for spray deposits depend on the target nature, tracer substance, and target-tracer interactions.

The quantitative methods to assess spray deposition of different types of tracers are colorimetry, fluorometry and spectrometry.

\subsubsection{The Fluorescent Tracers}

The fluorescent tracer dyes are widely used in researches studies to evaluate the amount of droplet deposit on and out the target area because of their very low level of detection. First uses were related by Speelman (1971) and Barry (1978). These tracers are not analytically expensive compared to the extraction and the chromatographic analyzes of pesticides, also the fact of being less harmful during the experiments. Palladini $\&$ al. (2005) employed a fluorescent pigment under ultraviolet light (UV) to assess the amount deposited on leaf. Fluorescent pigments used as tracers are not water soluble and require the addition of surfactants, which reduce the surface tension of the solution.

The fluorescents tracers like Brilliant Sulfo Flavine (BSF), Fluorescein, Eosine, Caracid, Brilliant Flavine, Tinopal, Pyranine, Rhodamine A, Uvitex, Uranin are analyzed by spectrofluometry (Nuyttens et al., 2007b)

The weakness of these tracers is their sensibility to the light. Most of the fluorescent dyes are sensitive to light and photodegraded during exposition to solar radiation. Thus, it is necessary to verify the recovery and stability of the tracer on the target collector prior to the start of the experimentation.

Cai and Stark (1997) tested several fluorescent dyes and concluded that the BSF had the better performance. It was selected as the best tracer to replicate the comportment of pesticide during atmospheric spraying, since its degradation is only $11 \%$ after 8 hours of exposure to sunlight. This dye was then used by several authors (see for instance, Holterman et al., 1997; Gil \& Sinfort; 2005).

Tracers have many other advantages that have been the subject of several researches. For example, Hewitt \& al. 1994 showed that fluorescent dyes Rhodamine and BSF do not influence the droplet size spectra during spray evaluation measurement. Also, Palladini et al. (2005) proved that the Brilliant Blue and Saturn Yellow mixture at $0.15 \%$ is stable under all tested conditions, not absorbed by the leaves surface and maintained the same surface tension as that of water.

\subsubsection{The Colorimetric Tracers}

Some of visible dyes are also used like Tartrazine, Erythrosine, Lissamine Green and Orange, and Brilliant blue are measured with colorimetric methods (Murray et al., 2000). For instance, Salyani and Whitney, (1988) used colorimetry for copper detection on leaves, Forster et al. (2005) used tartrazine to measure deposits on plants. Tartrazine was used also to assess deposition on vineyard and artificial vineyard to evaluate the efficacy of spray equipment (Codis et al., 2013).

The dye degradation, and adsorption propriety of tracer on plant can be a problem, and generate errors in evaluating the deposition on the plant, different experimentation of recovery must be preceded. To remedy this anomaly, Teske et al. (2002) used pesticide Chlorpyriphos with and without florescent tracers to determine the droplet size after impact on different types of crops leaves. In this spirit, Cerqueira et al. (2012) used a mixture of tracer pesticide (Tebuconazole) with fluorescent dye (Rhodamine B, Brilliant blue), Metal ions (Cobox) and Sodium chloride (Salt) to compare spray deposit on different crops with an artificial paper filter target. But combinations between different types of mixture tracers is to be used with caution because they can decrease the extraction coefficients below the limit and the cost of the analyzes of the ions tracers and the pesticides can be relevant. 


\subsubsection{Metal Ions}

The use of metallic tracer analyzed with mass spectrometry is another possibility for the measurement of pesticide deposits. Cerqueira et al. (2012) reported that the first metal ions used as spray tracers was the copper as the analyte for the measurement of deposits fungicides containing metal like copper oxychloride, also Metallic Salts, Copper Hydroxide, Metal chelates (cobalt, zinc, manganese, borium, etc.) was used. These mineral chelates, considered as horticultural leaf fertilizers must be used in normal concentrations to not harm the plant (Foqué et al., 2014). These metal chelates are easily available as foliar nutrients, also used as tracers and measured spray deposition by Atomic Absorption Spectroscopy (AAS) or by Inductively Coupled Plasma analyzes (ICP) coupled with Mass Spectrometry (MS) for the very low concentration (Nuyttens et al., 2004).

Braekman et al. (2009) tested many metal ions as spray tracers like Zinc, Manganese, Strontium and Copper. They are light stable, soluble in water sand can be measured at very low concentrations in $\mathrm{ng} \mathrm{L}^{-1}$ and perform similarly as pesticide. The recovery of the copper analyzed by atomic absorption spectrometry was evaluated more than $99 \%$.

The use of metal ions is complex, very expensive and need much time for analyzes.

\subsection{Chemical Analyzes}

The sequence steps in pesticide analyzes are matrix modification, extraction, clean-up and determination. The sampler is first drawn through an adsorbent, then the molecule is extracted and analyzed.

To measure low concentrations highly selective, sensitive and accurate, analytical methods are needed. In recent years, the two analyzes techniques conventionally used are Gas Chromatography (GC) and Liquid Chromatography (LC) associated with different selective and sensitive detectors, such as Mass Spectrometry (MS). These most often involve separation techniques that rely on a difference in behavior of the components to be analyzed between a mobile phase and a stationary phase. Gas chromatography (GC) coupled with tandem mass spectrometry (MS/MS) is one of the most common methods for the determination of pesticide concentration in the environment (De Rossi et al., 2003). The components are extracted and analyzed by GC using a detector. Most GC methods employ element-selective detectors such as electron capture detector (ECD), nitrogen-phosphorus detector, flame photometric detector, electrolytic conductivity detector and microwave-induced plasma-atomic emission detection (Chen et al., 1996). GC-MS/MS is a powerful tool for the identification and quantification of pesticides in complex matrices during application and for post-application emissions. This technique has a better sensitivity and provides much more information on the components than in simple mass spectrometry or GC coupled with other detectors such as ionization flame (FID). It has already been used for the quantification of pesticides in the soil (Frenich et al., 2005), in the air (Miller et al., 2000) and in vegetables (Carabias-Martínez et al., 2007). Several investigators have studied different sampler types from different matrices for GC/MS analyzes (Meghesan-Breja \& Morar, 2012; Lozano et al., 2012). They all agree that concentrations of analyzed components depend strongly on the sampler and on sampling conditions, regardless of the origin of the sample.

So, besides the use of official methods, many laboratories develop and validate their own method for pesticide residues analyzes because depending on the analytical technique chosen, different approaches for sample treatment may be considered. Even when using the same technique, different equipment or equipment settings can be selected, making it difficult to reach a universally accepted analytical method.

For example, Meghesan-Breja (2012), developed a fast GC-MS method for 70 pesticides identification and quantification from soil. Carabias-Martínez et al. (2007) used a specific method to determine triazines in potato, carrot, lettuce, bean, zucchini and orange. Another group of researchers managed to extract 29 carbamates from dried fruits (raisin, prune and mango), spices (turmeric, masala, sage, thyme and red pepper) and from soybean paste and soy sauce (Terada et al., 2008).

\subsection{Spray Droplets Collectors}

Regardless of the method of the deposition evaluation, collectors should be selected and used to recover the deposits to be measured, whether on the ground, on the plant, in the air or in surface water.

Several types of collectors were used by scientific community, namely: natural collectors, artificial collectors, Water Sensitive Paper (WSP), Polyethylene Collectors, etc. All those samplers can be used to evaluate deposition from aerial or terrestrial spray application.

After spraying, deposits are recovered by washing the collectors with a given amount of water and the concentration is later determined by analyze. 


\subsubsection{Naturals Collectors}

The real plant canopy can provide the information about the amount of spray deposits retained on the foliage.

The distribution and amount of product deposited on the target determines the success of phytosanitary practices (Cerqueira et al., 2012).

Plant leaves are natural samplers that can be washed top and bottom with solvents to extract and quantify total fluorescent tracer amounts, but individual droplet data are difficult to extract from these natural collectors (Martin, 2014).

With this technique, the crop vegetation density is an important factor to consider. To describe it, some like as Da Silva et al. (2002) used the Leaf Area Density (LAD) (Note 3). But the majority of researchers have relied on the Leaf Area Index, (LAI), defined as the ratio of leaf area to the soil surface $\left[\mathrm{m}^{2} / \mathrm{m}^{2}\right]$. Gyldenkærne et al. (1999) found that ground deposit is a function of several factors, among them, the canopy density which may be expressed in LAI. To calculate the deposition at a given level (i) in the canopy, authors proposed a capture coefficient Ki depending on that level. In the literature, the measurement of the leaf area index could be direct, for example by using an optical planimeter (Alem et al., 2002), or indirectly by measuring the light energy incident under the leaves with a radiometer. This method is faster than the direct one, but it is not accurate and it requires specific hardware.

\subsubsection{Artificial Collectors}

The scientific community used for some time artificial collectors as replacements for natural foliage. This is related to the fact that the recovery of sprayed tracer retained on natural plant surfaces is more difficult and more expensive than from artificial targets. In addition, the limit of the accuracy to quantify the surface area of the natural plant targets (Forster et al., 2014).

Cerqueira et al. (2012) conducted Lab tests to compare methods for deposits quantification using different tracers on artificial and natural targets. They concluded that, globally, artificial targets, were more efficient in recovering the spray deposits.

Bahrouni et al., (2010) selected small plastic carpets sizing $20 \mathrm{~cm} \times 30 \mathrm{~cm}$ to measure ground depositions, under wheat plants. Their efficiency was measured by comparing the amounts collected on the carpets to the amounts measured on the same width on a patternator: it was about $80 \%$. To trap the sprayed droplets in the air, the authors used Polyvinyl chloride (PVC) line of $2 \mathrm{~mm}$ diameter that was tested by Gil et al. (2007). Its efficiency was also about $80 \%$. To measure the amounts of deposits on weeds, the method was to cut the entire plant which acted then as a collector. Foqué et al. (2012) used filet paper collectors (FPC) to monitor spray distribution and penetration in the canopy by using leaf fertilizers. The FPC are used as artificial targets because of their uniformity in size, absorpting properties and non-waxy surface. The FPC have the properties to be less susceptible to bouncing of droplets than real leaves and they give a better indication of the efficacy of the spray application technique to reach a certain location in a crop (Foqué et al., 2014).

The extraction coefficient is generally higher for artificial targets, except for the Brilliant Blue tracer, for filter paper collector, lower than the limit $(80 \%)$ of extraction established by (ANVISA, 2008) for validation of the analytical methods. The use of artificial collectors for spray characterization is well known using all collector types was useful to properly characterize the sprays and to quantify the differences between each collector type for coverage and droplet density (Ferguson, 2016).

\subsubsection{Water Sensitive Paper (WSP)}

The water sensitive paper is another type of artificial collector to perform a qualitative assessment of deposits. It is an excellent collector to test sprayer set-up, but does not gives an idea about the efficacy of the formulations, retention and coverage proprieties on crop surface. Halley et al. (2008) used a combination of treated wheat heads and water sensitive paper to compare various application parameters for treating wheat heads. Salyani et al (2013) used WSP to assess the spray distribution on crop and proof the limitations of WSP in characterizing spray droplet distribution and deposition in field application. The small droplets are easily measured on WSP collector than the larger droplets, higher volume rate. The measurement of droplet size spectra can be conducted using non-intrusive laser equipment or with a variety of droplet collection and measurement systems. According to Hoffmann and Hewitt, 2005, the WSP can be used as a method for assessing the droplet size spectra and deposition quality for agrochemicals application. They are used also to visualize and quantify spray distribution deposed from terrestrial or/and aerial applications. The spray droplet leaves a blue stain on the yellow surface of WSP which coated with a layer of bromoethyl blue during treatment with water contact. The WSP are usually employed to quality the distribution of different configurations of types of sprayers, nozzles, pressure on 
vegetation (Nuyttens et al., 2004). The WSP will turn blue under high humidity conditions more than $85 \%$. The blue stain created by a water droplet is larger than the actual droplet due to spreading in a leaves surface. Therefore, a spread factor must be used to calculate the actual droplet that created a particular stain size (Hoffmann \& Hewitt, 2005). The WSP does not require a fluorescent dye tracer in the mixture and can be analyzed by software to yield droplet data but the WSP spoil easily at high humidity and do not capture very well small droplets less than $50 \mu \mathrm{m}$.

The droplet deposit on WSP can be measured with Image analyzes system software (Salyani et al., 2013). The WSP cards droplet scan is processed with CCD camera, software program Droplet Scan and Swath Kit. The results given by analyzing of the WSP with the three imaging systems are comparable (Fritz et al., 2009).

The droplet spectra on WSP are analyzed with specialized imaging equipment and software.

\subsubsection{Polyethylene Collectors}

The spray impact behaviors on superhydrophobic leaves surface can be measured on an artificial superhydrophobic surface like in (Massinon \& Lebeau, 2012). The authors employed an artificial superhydrophobic surface composed of complete polytetrafluoro-ethylene (PTFE) coated microscope slide blade to measure spray deposition on wheat and barley leaves. Some others used and confirmed the efficacy of many others artificial targets like as glass slides, strings, monofilament lines, mesh screens and plastic soda straws (Martin et al., 2014).

Forster et al. (2014) tested other artificial collectors to assess plant retention (Mylar sheet, water sensitive paper, steel plate, a plastic Petri dish). They found that all those targets were poor indicators of adhesion and retention on natural plant surfaces. Garcerá et al. (2012) used the white PVC sheet as artificial collectors of the spray solution formulations tested to assess the drop retention behavior on citrus leaves due to their similarity of skins and drop distribution pattern. This collector was also used by Codis et al. (2013) as a leaves crop of the artificial vineyard to assess the efficacy of spray equipment used in spray protection. The two teams approved a good recovery rate for this artificial target.

Despite these results, which favor the use of artificial collectors, Hewitt (2010) has a different opinion. He explained that these artificial targets should not be substituted the natural plant surfaces in field trials for assessing spray crop retention. He thought that the wettability differences between artificial targets didn't have been considered in many studies.

\section{Conclusion}

This review article shows the importance of pesticides ground deposits on the pollution of the environment and the necessity to understand the plant retention mechanisms to limit the deposit rate. Retention efficiency of spray droplets is a complex problem depending mainly on physical equipment parameters determining strongly the droplet size, climatic conditions, physiochemical properties of the diluted spray formulation and surface characteristics of the target plant. Depending on the interaction of those parameters, the possible outcomes of droplets impacting the leaf surface are potentially adhesion, rebound or shatter. So, their fate can be retention, slide on the soil, evaporation or adsorption on the target surface. To better understand the phenomenon, modelling could be a suitable solution, but more efforts should be directed toward studies to characterize the complicated interaction between spray droplets and plants considering the different involved parameters.

To directly measure pesticides deposits, through natural or artificial collectors, Gas Chromatography coupled with tandem Mass Spectrometry (MS/MS) is one of the most common used methods. However, because of the danger of the active substances and the requirement of meticulous and expensive laboratory analyzes, tracer and dyes are commonly recommended to replicate the comportment of pesticides. But in this case, it is required to determine the efficiency factor of the combination tracer/collector and to validate the method. If the collector is the plant leaves, it is very important to consider the Leaf Area Index. Brillant Sulfo Flavine was selected by several researchers as the best tracer because of its performances and its adaptabilities to be used with different types of targets.

\section{References}

Alem, C., Labhilili, M., Brahmi, K., Jlibene, M., Nasrallah, N., \& Filali-Maltouf, M. (2002). Adaptations hydrique et photosynthétique du blé dur et du blé tendre au stress salin. Comptes Rendus-Biologies, 325(11), 1097-1109. https://doi.org/10.1016/S1631-0691(02)01531-7

ANVISA (National Agency for Sanitary Surveillance). (2002). Retrieved from http://www.anvisa.gov.br/ legis/resol/2002/475_02re.htm 
Bahrouni, H. (2010). Caractérisation de l'efficacité technique des systèmes de pulvérisation et des pertes de pesticides appliqués aux cultures basses dans les régions méditerranéennes, cas de la Tunisie (Thèse de doctorat Montpellier SupAgro-France/INAT, Tunisie). Retrieved from https://tel.archives-ouvertes.fr/ tel-00484346

Bahrouni, H., Sinfort, C., \& Hamza, E. (2010). An approach for pesticide loss estimation adapted to field crops in Mediterranean conditions. XVIIth World Congress of the International Commission of Agricultural and Biosystems Engineering (CIGR), Canadian Society for Bioengineering (CSBE/SCGAB), Québec City, Canada. Retrieved from http://www.csbe-scgab.ca/docs/meetings/2010/CSBE100947.pdf

Becker, F., Klein, A., Winkler, R., Jung, B., Bleiholder, H., \& Schmider, F. (1999). The degree of ground coverage by arable crops as a help in estimating the amount of spray solution intercepted by the plants. Nachrichtenbl. Deut. Pfanzenschutzd, 51(9), 237-242.

Boukhalfa, H. H., Massinon, M., Belhamra, M., \& Lebeau, F. (2014). Contribution of spray droplet pinning fragmentation to canopy retention. Crop Prot., 56, 91-97. https://doi.org/10.1016/j.cropro.2013.11.018

Braekman, P., Foqué, D., Van Labeke, M.-C., Pieters, J. G., \& Nuyttens, D. (2009). Influence of spray application technique on spray deposition in greenhouse ivy pot plants grown on hanging shelves. Hort. Science, 44, 1921-1927.

Cai, S. S., \& Stark, J. D. (1997). Evaluation of five fluorescent dyes and triethyl phosphate as atmospheric tracers of agricultural sprays. Journal of Environmental Science and Health Part B: Pesticides Contaminants and Agricultural Wastes, 32, 969-983. https://doi.org/10.1080/03601239709373123

Carabias-Martínez, R., Rodríguez-Gonzalo, E., Miranda-Cruz, E., Domínguez-Álvarez, J., \& Hernández-Méndez, J. (2007). Sensitive Determination of Herbicides in Food Samples by Non-Aqueous CE Using Pressurized Liquid Extraction. Electrophoresis, 28(20), 3606-3616. https://doi.org/10.1002/elps.200700254

Cerqueira, D. T. R., Raetano, C. G., Henrique, M., do Amaral Dal Pogetto, F., Prado, E. P. Christovam, R. S. Serra, M. E., \& Almeida Costa, S. I. (2012). Agricultural Spray Deposit Quantification Methods, American Society of Agricultural and Biological Engineers, Applied Engineering in Agriculture, 28(6), 825-831. https://doi.org/10.13031/2013.42474

Chen, Z. M., \& Wang, Y. H. (1996). Chromatographic methods for the determination of pyrethrin and pyrethroid pesticide residues in crops, foods and environmental samples. J. Chromatogr, 754(1-2), 367-95. https://doi.org/10.1016/S0021-9673(96)00490-6

Codis, S., Bonicel, J. F., Diouloufet, G., Douzals, J. P., Hébrard, O., Montegano, P., Ruelle, B., Ribeyrolles, X., \& Vergès A. (2013, June). EvaSprayViti: A new tool for sprayer's agro-environmental performance assessment. 12th Workshop on Spray Application Techniques in Fruit Growing Suprofruit 2013, Valencia, Spain.

Cox, S. J., Salt, D. W., Lee, B. E., \& Ford, M. G. (2000). A model for the capture of aerially sprayed pesticide by barley. Journal of Wind Engineering ,\& Industrial Aerodynamics, 87(2-3), 217-230. https://doi.org/10.1016/ S0167-6105(00)00038-6

Da Silva, A., Sinfort, C., Bonicelli, B., Voltz, M., \& Huberson, S. (2002). Spray penetration within vine canopies at different vegetative stages. Aspects of Applied Biology, 66, 331-339.

DG SANCO, European Union Reference Laboratory. (2010). EURL-FV, Multiresidue Method using QuEChERS followed by $G C-Q q Q / M S / M S$ and $L C-Q q Q / M S / M S$ for Fruits and Vegetables. Retrieved from http://www.crl-pesticides.eu/library/docs/fv/CRLFV_Multiresidue_methods.pdf

De Rossi, C., Bierl, R., \& Riefstahl, J. (2003). Organic pollutants in precipitation: Monitoring of pesticides and polycyclic aromatic hydrocarbons in the region of Trier (Germany). Physics and Chemistry of the Earth, 28, 307-314. https://doi.org/10.1016/S1474-7065(03)00052-4

De Ruiter, H., Uffing, A.-J. M., Meinen, E., \& Prins, A. (1990). Influence of Surfactants and Plant Species on Leaf Retention of Spray Solutions. Weed Science, 38(6), 567-572. https://doi.org/10.1017/S00431745 0005150

Ferguson J. C. (2016). Towards the optimization of coarse sprays to reduce drift and improve efficacy in Australian cropping systems (Thesis, University of Queensland). https://doi.org/10.14264/uql.2016.268 
FOCUS. (2002). Generic guidance for FOCUS groundwater scenarios (Version 1.1). Forum for Co-ordination of Pesticide Fate Models and Their Use. Retrieved from http://www.focus.jrc.ec.europa.eu/ public_path/projects_data/focus/gw/docs/Generic_guidance_forV1_1.pdf

Foqué, D., Dekeyser, D., \& Nuyttens, D. (2014). Accuracy of a multiple mineral tracer methodology for measuring spray deposition. Aspects of Applied Biology, 122, 203-212.

Foqué, D., Pieters, J. G., \& Nuyttens, D. (2012). Spray deposition and distribution in a bay laurel crop as affected by nozzle type, air assistance and spray direction when using vertical spray booms. Crop Protection, 41, 77-87. https://doi.org/10.1016/j.cropro.2012.05.020

Forster, W. A., Kimberley, M. O., \& Zabkiewicz, J. A. (2005). A universal spray droplet adhesion model. Transactions of the ASABE, 48, 1321-1330. https://doi.org/13031/2013.19179

Forster, W. A., Mercer, G. N., \& Schou, W. C. (2012). Spray droplet impaction models and their use within AGDISP software to predict retention. New Zealand Plant Protection, 65, 85-92.

Forster, W. A., Gaskin, R. E., Strand, T. M., Manktelow, D. W. L., \& Van Leeuwen, R. M. (2014). Effect of target wettability on spray droplet adhesion, retention, spreading and coverage: artificial collectors versus plant surfaces. NZ Plant Prot., 67, 284-291.

Frenich, G., Gonzalez Rodrıguez, M., Martınez Vidal, J., Arrebola, F., \& Hernandez Torres, M. (2005). A study of the disappearance of pesticides during composting using a gas chromatography-tandem mass spectrometry technique. Pest Manag Sci, 61, 458-466. https://doi.org/10.1002/ps.984

Fritz, B. K., Parker, C., Lopez Jr., J. D., Hoffmann, W. C., \& Schleider, P. (2009). Deposition and droplet sizing characterization of a laboratory spray table. Transactions of the ASAE, 25(2), 175-180.

Furmidge, C. (1962). Physico-chemical studies on agricultural sprays, iv. the retention of spray liquids on leaf surfaces. J. Sci. Food Agric., 13, 127-140. https://doi.org/10.1002/jsfa.2740130213

Garcerá, C., Moltó, E., Zarzo, M., \& Chueca, P. (2012). Modelling the spray deposition and efficacy of two mineral oil-based products for the control of Aonidiella aurantii (Maskell). Crop Prot., 31(1), 78-84. https://doi.org/10.1016/j.cropro.2011.10.004

Gil, Y., Sinfort, C., Brunet, Y., Polveche, V., \& Bonicelli, B. (2007). Atmospheric loss of pesticides above an artificial vineyard during air-assisted spraying. Atmospheric Environment, 41(14), 2945-2957. https://doi.org/10.1016/j.atmosenv.2006.12.019

Gil, Y., \& Sinfort, C. (2005). Emission of pesticides to the air during sprayer application: A bibliographic review. Atmospheric Environment, 39(28), 5183-5193. https://doi.org/10.1016/j.atmosenv.2005.05.019

Graham-Bryce I. J. (1977). Crop Protection: A Consideration of the Effectiveness and Disadvantages of Current Methods and of the Scope for Improvement. Trans. R. Soc. Lond. B., 281(980), 163-179. https://doi.org/ 10.1098/rstb.1977.0131

Gyldenkærne, S., Secher, B. J., \& Nordbo, E. (1999). Ground deposit of pesticides in relation to the cereal canopy density. Pesticide Management Science, 55(12), 1210-1216. https://doi.org/10.1002/(SICI)1096 -9063(199912)55:12<1210::AID-PS76>3.0.CO;2-6

Halley, S., Van Ee G., Hofman, V., Panigrahi, S., \& Gu, H. (2008). Fungicide deposition measurement by spray volume, drop size, and sprayer system in cereal grains. Applied Engineering in Agriculture, 24(1), 15-21. https://doi.org/10.13031/2013.24155

Hewitt, A. J., Sanderson, R., Huddleston, E. W., \& Ross, J. B. (1994). Aerial spray drift potential and droplet size spectra produced by spraying picloram with and without adjuvants: In pesticide formulations and application systems. ASTM STP, 1234-1994.

Hewitt A. J. (2001). Drift filtration by natural and artificial collectors: A literature review. Retrieved from https://fyi.uwex.edu/manureirrigation/files/2013/04/AG_DRIFT-DriftFiltrationLitReview-2001.pdf

Hewitt A. J. (2010). Tracer and collector systems for field deposition research. Asp. Appl. Biol., 99, $283-289$.

Hoffmann, W. C., \& Hewitt, A. J. (2005). Comparison of three imaging systems for water-sensitive papers. Applied Engineering in Agriculture. Technical Note, 21(6), 961-964.

Holterman, H., Van de Zande, J., Porskamp, H. J., \& Huijmans, J. (1997). Modelling spray drift from boom sprayers. Computers and Electronics in Agriculture, 19, 1-22. https://doi.org/10.1016/S0168-1699(97) 00018-5 
Jia, W., \& Zhu, H. (2015). Dynamics of water droplet impact and spread on soybean leaves. Transactions of the ASABE. American Society of Agricultural and Biological Engineers, 58(4), 1009-1016. https://doi.org/ 10.13031/trans.58.11147

Lozano, A., Rajski, L., Belmonte-Valles, N., Ucles, A., Ucles, S, Mezcuaa, M., \& Fernandez-Alba, A. (2012). Pesticide analyzes in teas and chamomile by liquid chromatography and gas-chromatography tandem mass spectrometry using a modified QuEChERS method: Validation and pilot survey in real samples. Journal of Chromatography A, 1268, 109-122. https://doi.org/10.1016/j.chroma.2012.10.013

Martin Daniel, E. (2014). A fluorescent imaging technique for quantifying spray deposits on plant leaves. Atomization and Sprays, 24(4), 367-373. https://doi.org/10.1615/AtomizSpr.2014008462

Massinon, M., \& Lebeau, F. (2012). Experimental method for the assessment of agricultural spray retention based on high-speed imaging of drop impact on a synthetic superhydrophobic surface. Biosyst. Eng., 112(1), 56-64. https://doi.org/10.1016/j.biosystemseng.2012.02.005

Massinon M., \& Lebeau, F. (2013). Review of physicochemical processes involved in agrochemical spray retention. Biotechnology, Agronomy, Society and Environment, 17(3), 494-504.

Massinon, M., De Cock, N., Forster, W. A., Nairn, J. J., McCue, S. W., \& Zabkiewicz, J. A. (2017). Spray droplet impaction outcomes for different plant species and spray formulations. Crop Protection, 99, 65-75. https://doi.org/10.1016/j.cropro.2017.05.003

Meghesan-Breja, A., \& Morar, F. (2012). Multiresidue analyzes of 70 pesticides from soil by gas chromatography-time-of-flight mass spectrometry GC TOF-MS. The 6th edition of the Interdisciplinarity in Engineering International Conference "Petru Maior", University of Tîrgu Mureş, Romania. Retrieved from http://inter-eng.upm.ro/2012/files/proceedings/papers/paper34.pdf

Mercer, G. N., Sweatman, W. L., Elvin, A., Caunce, J., Fulford, G., \& Harper, G. (2007). Process driven models for spray retention in plants. In G. Wake (Ed.), Proceedings of the Mathematics in Industry study group (pp. 57-85). Retrieved from http://www.maths-in-industry.org/miis/75/2/spray_full.pdf

Miller, D. R., Stoughton, T. E., Steinke, W. E., Huddleston, E. W., \& Boss, J. B. (2000). Atmospheric stability effects on pesticide drift from an irrigated. https://doi.org/10.13031/2013.2998

Murray, R., Cross, J., \& Ridout, S. (2000). The measurement of multiple spray deposits by sequential application of metal chelate tracer. Annals of Applied Biology, 137, 245-255. https://doi.org/10.1111/j.1744-7348. 2000.tb00065.x

Nairn, J. J., Rorster, W. A., \& Leeuwen, V. (2013). Universal spray droplet adhesion model accounting for hairy leaves. Weed Res., 53(6), 407-417. https://doi.org/10.1111/wre.12039

Nuyttens, D., Windey, S., \& Sonck, B. (2004). Comparison of operator exposure for five different greenhouse spraying applications. Journal of Agricultural Safety and Health, 10(3), 187-195. https://doi.org/10.13031/ 2013.16475

Nuyttens, D., De Schampheleire, M., Baetens, K., \& Sonck, B. (2007a). The influence of operator-controlled variables on spray drift from field crop sprayers. Transactions of the ASABE, 50(4), 1129-1140. https://doi.org/10.13031/2013.23622

Nuyttens, D., Baetens, K., De Schampheleire, M., \& Sonck, B. (2007b). Effect of nozzle type, size and pressure on spray droplet characteristics. Biosystems Engineering, 97(3), 333-345. https://doi.org/10.1016/j.biosy stemseng.2007.03.001

Olofsdotter, M., \& Streibig, J. C. (1997). Deposits of pesticides on the soil surface (Peticides Research No. 27). København: Ministry of Environment and Energy, Denmark.

Palladini, L. A., Raetano, C. G., \& Velini, E. D. (2005). Choice of tracers for the evaluation of spray deposits. Sci. Agric, 62(5), 440-445. https://doi.org/10.1590/S0103-90162005000500005

Salyani, M., \& Withney, J. D. (1988). Evaluation of methodologies for field studies of spray deposition. Transactions of the ASAE, 31(2), 390-395. https://doi.org/10.13031/2013.30720

Salyani, M., Zhu, H., Sweeb, R. D., \& Pai, N. (2013). Assessment of spray distribution with water-sensitive paper. AgricEngInt: CIGR, 15(2), 101.

Taylor, W. A., \& Shaw G. B. (1983). The effect of drop speed, size and surfactant on the deposition of spray on barley and radish or mustard. Pestic. Sci., 14, 659-665. https://doi.org/10.1002/ps.2780140614 
Taylor, P. (2011). The wetting of leaf surfaces. Current Opinion in Colloid, \& Interface Science, 16(4), 326-334. https://doi.org/10.1016/j.cocis.2010.12.003

Terada, H., Noguchi, S., Maruyama, Y., Kato, H., Tamura, Y., \& Oka, H. (2008). Analytical Method for Carbamate Pesticides in Processed Foods by LC/MS/MS. Journal of the Food Hygienic Society of Japan, 49(3), 125-135. https://doi.org/10.3358/shokueishi.49.125

Teske, M. E., Bird, S. L., Esterly, D. M., Curbishley, T. B., Ray, S. L., \& Perry, S. G. (2002). AgDRIFT®: a model for estimating near-field spray drift from aerial applications. Environmental Toxicology and Chemistry, 21, 659-671. https://doi.org/10.1002/etc.5620210327

Wilson, K. C., Horsley, R. R., Kealy, T., Reizes, J. C., \& Horsley, M. (2003). Direct prediction of fall velocities in non-Newtonian materials. Int. J. of Mineral Proc, 71(1-4), 17-30. https://doi.org/10.1016/S0301-7516 (03)00027-9

Wolf, T. M., Caldwell, B. C., Pederson, J. L., \& Cessna, A. J. (2004). Interaction of riparian vegetation and nozzle type for drift deposit reduction. Aspects of Applied Biology, 71, 183-190.

Xu, L., Zhu, H., Ozkan, E., \& Bagley, W. E. (2011). Droplet evaporation and spread on waxy and hairy leaves associated with type and concentration of adjuvants, Pest Manag. Sci., 67(7), 842-51. https://doi.org/ $10.1002 /$ ps.2122

Yates, W. E., \& Akesson, N. B. (1963). Fluorescent tracers for quantitative microresidue analyzes. Transactions of the ASAE, 6(2), 105-114. https://doi.org/10.13031/2013.40838

Zwertvaegher, I. K. Verhaeghe, M., Brusselman, E., Verboven, P., Lebeau F., Massinon M., ... Nuyttens, D. (2014). The impact and retention of spray droplets on a horizontal hydrophobic surface. Journal of Biosystems Engineering, 126, 82-91. https://doi.org/10.1016/j.biosystemseng.2014.07.013

\section{Notes}

Note 1. Biologische Bundesanstalt, Bundessortenamt und Chemische Industrie: Federal Center for Biological Research for Agriculture and Forests in Germany.

Note 2. DV10, DV50 and DV90 indicates respectively that $10 \%, 50 \%$ and $90 \%$ of the spray volume is composed of drops whose diameters are smaller than this value $(\mu \mathrm{m})$.

Note 3. Ratio of leaf area to considered vegetation volume $\left[\mathrm{m}^{-1}\right]$.

\section{Copyrights}

Copyright for this article is retained by the author(s), with first publication rights granted to the journal.

This is an open-access article distributed under the terms and conditions of the Creative Commons Attribution license (http://creativecommons.org/licenses/by/4.0/). 